\title{
Temperature Increase in the Fetus Exposed to UHF RFID Readers
}

\author{
Serena Fiocchi*, Marta Parazzini, Ilaria Liorni, Theodoros Samaras, and Paolo Ravazzani
}

\begin{abstract}
Exposure to electromagnetic fields (EMFs) has prominently increased during the last decades due to the rapid development of new technologies. Among the various devices emitting EMFs, those based on Radio-frequency identification (RFID) technologies are used in all aspects of everyday life, and expose people unselectively. This scenario could pose a potential risk for some groups of the general population, such as pregnant women, who are expected to be possibly more sensitive to the thermal effects produced by EMF exposure. This is the first paper that addresses the estimation of temperature rise in two pregnant women models exposed to ultrahigh frequency RFID by computational techniques. Results show that the maximum temperature increase of the fetus and of the pregnancy-related tissues is relatively high (even about $0.7^{\circ} \mathrm{C}$ ), not too far from the known threshold of biological effects. However, this increase is confined to a small volume in the tissues.
\end{abstract}

Index Terms-Fetus, radio frequency identification (RFID), temperature.

\section{INTRODUCTION}

$\mathbf{I}$ $\mathrm{N}$ the last decades, the broad use of wireless systems and the consequent increase in the number of wireless devices have noticeably changed EMF exposure patterns, levels, and scenarios. These changes include the increase of exposure levels, the extension of that exposure to almost all societal classes, a longer time of exposure, and the exposure to devices that operate at frequencies at which the biological effect is still unexplored.

Among the countless number of wireless communication systems, one of the most promising and fast growing makes use of the radio-frequency identification (RFID) technology. It is based on the communication between a reader and a label (named "tag") which uniquely and fast identifies the target, either an

Manuscript received July 18, 2013; revised February 3, 2014 and February 28, 2014; accepted March 6, 2014. Date of publication March 14, 2014; date of current version June 14, 2014. Asterisk indicates corresponding author.

${ }^{*}$ S. Fiocchi is with the Istituto di Elettronica e di Ingegneria dell' Informazione e delle Telecomunicazioni, CNR Consiglio Nazionale delle Ricerche, 20133 Milan, Italy (e-mail: serena.fiocchi@ieiit.cnr.it).

M. Parazzini and P. Ravazzani are with the Istituto di Elettronica e di Ingegneria dell'Informazione e delle Telecomunicazioni, CNR Consiglio Nazionale delle Ricerche, 20133 Milan, Italy (e-mail: marta.parazzini@ieiit.cnr.it; paolo.ravazzani@ieiit.cnr.it ).

I. Liorni is with the Dipartimento di Elettronica, Informazione e Bioingegneria DEIB, Politecnico di Milano, 20133, Milan, Italy, and also with the Istituto di Elettronica e di Ingegneria dell'Informazione e delle Telecomunicazioni, CNR Consiglio Nazionale delle Ricerche, 20133 Milan, Italy (e-mail: ilaria.liorni@polimi.it ).

T. Samaras is with the Department of Physics, Aristotle University of Thessaloniki, 54124 Thessaloniki, Greece (e-mail: theosama@auth.gr).

Color versions of one or more of the figures in this paper are available online at http://ieeexplore.ieee.org. object or a subject [1]. RFID systems are used in many ubiquitous applications that can take advantage of automatic identification, such as asset tracking, supply chain management, payment systems, security and access control, transport systems, electronic passports and ID cards, animal identification, medical applications, and sports events. Among the different operating frequencies of RFID systems, the ultrahigh frequency (UHF) band (i.e., in the frequency range $870-915 \mathrm{MHz}$ ), is used in a great range of applications that require long read ranges. Subjects who occasionally or accidentally find themselves close to an RFID reader are exposed to RF radiation (note that of the two components of an RFID system, the reader emits the largest amount of EMF radiation, continuously according to the set duty cycle). Among them, pregnant women and their fetuses are considered more potentially susceptible to that exposure than others [2]. This, therefore, makes urgent the estimation of the actual levels of EMF to which they are exposed. At the UHF band, the known biological effect induced by EMF exposure is the temperature increase in the tissues. The pattern of EMF energy absorption is a complex function of several parameters, which can produce a nonuniform heating of tissues, which represents a challenge to the thermoregulatory system [3]. The International Commission on Non-Ionizing Radiation Protection (ICNIRP), in a comprehensive review aimed at providing guidelines for limiting exposure [4], concludes: "established biological and health effects in the frequency range from $10 \mathrm{MHz}$ to a few gigahertz are consistent with responses to a body temperature rise of more than $1{ }^{\circ} \mathrm{C}$." ICNIRP has proposed the specific absorption rate (SAR), which is the EMF power absorbed per mass by a body/tissue, as the metric to quantify, eventually, the potential heating of the body. Therefore, the most studies dealing with the assessment of the RF exposure levels in pregnant women and fetuses hold up to the SAR estimation (see, e.g., [5]-[10]), but, as suggested by various authors [11]-[15], the link between these two quantities is far from univocal. However, there are studies [16]-[20] that went one step further by estimating the increase in the fetal temperature due to RF exposure. In the last years, this is usually performed by computational methods based on the application of the BioHeat equation (BHE) introduced in [21] that takes into account the influence of the thermoregulation system. This effect should be considered potentially even more significant in the case of fetuses, taking into account the peculiarities of their physiology. The metabolic rate of the fetus, i.e., its metabolic heat production, is higher than that of a woman, and hence, its temperature remains $0.3-0.5^{\circ} \mathrm{C}$ higher than that of the pregnant woman [22]. Consequently, the heat is transferred from the fetus to the pregnant woman (heat loss). If the heat production and the heat loss remain balanced, the fetal temperature remains constant. Conversely, if the heat 

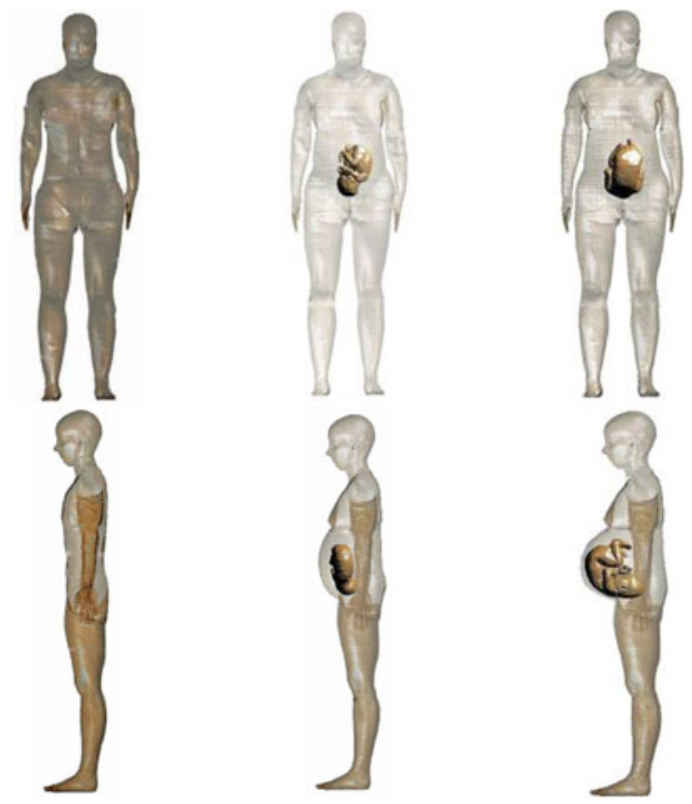

Fig. 1. Coronal (first raw) and sagittal (second raw) view of the Ella and the seven months and nine months GA pregnant women models.

transfer toward the woman is disturbed for any reason, the temperature of the fetus may change. Many biological, chemical, and physical agents can change the temperature of either the fetus or the woman, and thus, they can disturb normal fetal thermoregulation. The prolonged exposure to $\mathrm{RF}$ radiation has been suggested to be one of those agents [23].

In a recent paper [24], the assessment of exposure to UHF RFID devices of pregnant and nonpregnant women resulted in high levels of SAR values in some fetal and maternal tissues. The maximum peak of the SAR levels, as averaged over $10 \mathrm{~g}$ and normalized to $1-\mathrm{W}$ radiated power of the reader antenna, were found close to the limit of $2 \mathrm{~W} / \mathrm{kg}$, proposed by the ICNIRP guidelines [6]. However, a complete health risk assessment needs additional information on the fetal temperature increase. This paper aims to close this gap of knowledge, investigating the temperature increase in the same exposure scenarios as in [24], applying the classical approach based on the numerical solution of the BHE.

\section{MATERiAl And Methods}

\section{A. Anatomical Models and Exposure Scenarios}

The two pregnant woman models (seventh and ninth month of gestational age, GA) were obtained from partial deformations of the womb of the adult female model named "Ella" of the virtual population [25], [26] (see Fig. 1). In particular, the seven-month pregnant woman model was obtained by integrating in "Ella" the segmented MR images of a pregnant woman abdomen, whereas the ninth month is based on that of the seventh month, but the fetus model was replaced by a model of a scaled newborn [26]. In addition to fetal tissues, the placenta and the amniotic fluid (and the umbilical cord for the seven-month pregnant woman only) were also integrated in the anatomical models to complete the pregnant woman models. To sum up, the seven-month and
TABLE I

RANGE OF VARIABILITY OF SOME REFERENCE [27] PRENATAL TYPICAL MEASUREMENT AND REFERENCE [1] MASSES SET ACCORDING TO THE GA IN COMPARISON WITH THE CORRESPONDENT MEASUREMENTS AND MASSES OF THE FETAL MODELS

\begin{tabular}{lcccc}
\hline & $\begin{array}{c}\text { ICRP } \\
\text { Ref }(25- \\
30\end{array}$ & $\begin{array}{c}7 \text { months } \\
\text { fetus } \\
\text { weeks })\end{array}$ & $\begin{array}{c}\text { ICRP Ref } \\
(33-38 \\
\text { weeks })\end{array}$ & $\begin{array}{c}9 \text { months } \\
\text { fetus }\end{array}$ \\
\hline FETUS & & & & \\
\hline Mass (kg) & $0.99-1.7$ & 1.42 & $2.3-3.5$ & 2.78 \\
CRL (mm) & $185-235$ & 210 & $265-315$ & 270 \\
BPD (mm) & $65-79$ & 79 & $82-92$ & 81.2 \\
& & & & \\
\hline FETAL TISSUES & MASS $(g)$ & & & \\
\hline Brain & $120-200$ & 285 & $263-370$ & 280.4 \\
Hearth & $6.0-9.9$ & 13.0 & $12.7-20$ & 20.5 \\
Kidney & $7.6-13$ & 34.0 & $17-25$ & 20.5 \\
Liver & $38-63$ & 44.3 & $83-130$ & 95.4 \\
Lungs & $26-38$ & 19.7 & $45.5-60$ & 41.0 \\
Spleen & $1.1-2.7$ & 4.6 & $4.2-9.5$ & 9.0 \\
Thyroid gland & & & $0.8-1.3$ & 0.5 \\
Adrenal & & & $3.8-6$ & 2.6 \\
glands & & & $4.2-5$ & 1.8 \\
Pancreas & & & $7.8-13$ & 6.1 \\
Thymus & & & & \\
\hline
\end{tabular}

nine-month pregnant women models consist of 96 and 104 tissues, respectively. Table I shows the comparison between some typical anthropometric parameters measured on the fetus models with respect to the range of the reference values of the same parameters for fetuses at the same GA. This was done to verify the accuracy of the models used here. In particular, the second and the fourth column describe the range of variability of the corresponding quantity shown in the first column as reported in [27], while the third and the fifth ones show the magnitude of the same quantity as in the voxel models used here. The "Crown-rump length" is the measurement of the length of human fetuses from the top of the head (crown) to the bottom of the buttocks (rump) with the fetus in the natural curled position. It is a typical anthropometric measurement determined from ultrasound imagery and it is strictly correlated with the GA. The "Biparietal diameter" is another common fetal measurement which serves as a measure of the growth of the head. From that table, it is evident that both these lengths together with the fetal mass, measured on the fetus models fall within the range of the reference values for both models, indicating that they are globally realistic. On the contrary, the discrepancy among the fetal tissues' masses and the reference values is to suggest that the specific morphology of the organs of the models is affected by some errors (due to MRI quality data and/or segmentation and $3-\mathrm{D}$ reconstruction process) which could change the reliability of the results. Therefore, the results variability has been evaluated by estimating the uncertainty budget of the maximum of the temperature increase of the fetal body due to the variation of the mass of the fetal tissues. These latter have been considered equal to the minimum, the maximum, and the mean of the ranges as shown in Table I by adjusting the densities of the corresponding fetal tissues.

The RFID reader, as described in [24], was modeled as a circularly polarized patch antenna fed with a sinusoidal voltage source of $1-\mathrm{V}$ amplitude, $50-\Omega$ resistance at $870 \mathrm{MHz}$, the 


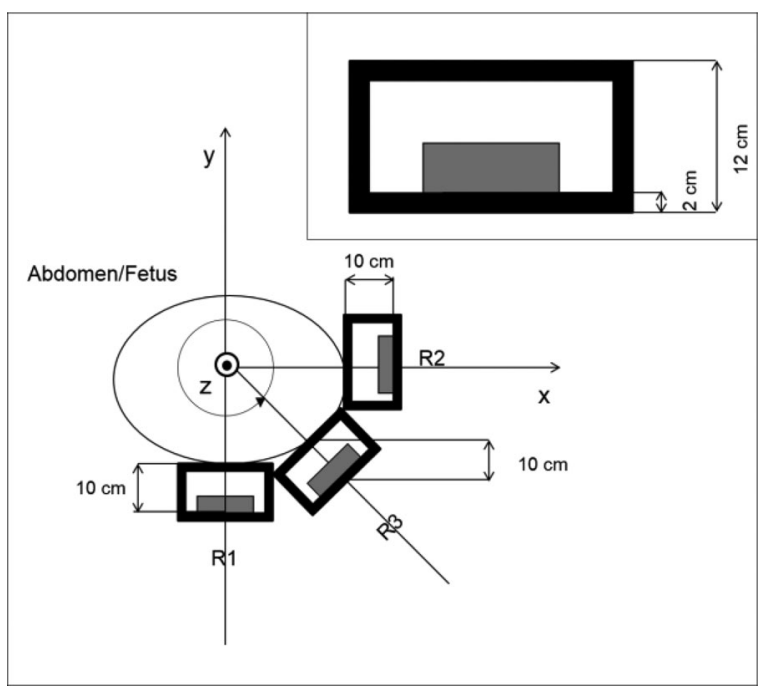

Fig. 2. Schematic representation of the whole reader system (i.e., antenna plus radome) position with respect to the pregnant women models as in [24], view from above. The center of the local coordinate systems was found through the arithmetic mean of maximum and minimum $x-, y$-, and $z$-coordinates (of the original reference system outside the body) of the pregnant women wombs, while the $x-, y$-,and $z$-axis were kept parallel to the original reference system. The center of the ground plane of the reader antenna was placed at $z=0$ (local coordinate systems) and at a distance of $10 \mathrm{~cm}$ from the skin of the model, along the direction defined by the respective angle: R1 $\left(-90^{\circ}\right), \mathrm{R} 2\left(0^{\circ}\right)$, and R3 $\left(-45^{\circ}\right)$ with respect to $x y$ plane. The upper right panel shows the dimension of the radome.

TABLE II

MAXIMUM SAR LEVELS (PSSAR $10 \mathrm{~g}$ ) IN FETAL TISSUES DUE TO UHF RFID EXPOSURE

\begin{tabular}{ccc}
\hline psSAR $_{l 0 \mathrm{~g}}(\mathrm{~W} / \mathrm{kg})$ & 7 months fetus & 9 months fetus \\
\hline R1 & 0.53 & 1.14 \\
R2 & 0.46 & 0.16 \\
R3 & 0.46 & 1.97 \\
\hline
\end{tabular}

typical frequency of the UHF RFID applications in Europe. The temperature increases in fetal tissues were estimated for the exposure scenarios identified as the "worst-case" ones in terms of SAR found in the previous paper [24], where, in particular, the ground plane of the reader antenna is placed at $10 \mathrm{~cm}$ from the pregnant and nonpregnant woman skin (see Fig. 2). Table II shows the fetal corresponding SAR levels [24]. These are the "worst-case" scenarios from a geometrical perspective because the radome of the antenna system is placed as close as possible to the abdomen skin. In other words, moving toward the skin from the antenna ground plane, one can encounter for $2 \mathrm{~cm}$ the radome, for $8 \mathrm{~cm}$ the cavity where the antenna is placed, and again the radome for additional $2 \mathrm{~cm}$. Hence, the minimum possible distance between the skin and the ground plane is $10 \mathrm{~cm}$ (see Fig. 2). Although theoretically higher temperature increases are expected for an antenna placed closer to the abdomen skin (for an antenna in air and next to the skin, the temperature rise decreases monotonically with the distance), the ones used in this study represent realistic worst-case scenarios considering commercial RFID readers (i.e., antenna plus radome). This consideration is in line with the behavior of SAR with the distance of the RFID antenna from the skin as shown in [24].

\section{B. Thermal Model}

Temperature increase inside the tissues exposed to EMF generated by the UHF RFID system was calculated using the BHE [21] as implemented by the thermal solver of the simulation platform SEMCAD X (Schmid \& Partner Engineering AG, Zurich, Switzerland) [28]. This provides a finite different solution of the BHE

$$
\rho c \frac{\partial T}{\partial t}=\nabla \cdot(k \nabla T)+\rho Q+\rho S-\rho_{b} c_{b} \rho \omega\left(T-T_{b}\right)
$$

where $T\left({ }^{\circ} \mathrm{C}\right)$ is the temperature of the tissue; $t$ (seconds) is the time; and $\rho\left(\mathrm{kg} / \mathrm{m}^{3}\right), c\left(\mathrm{~J} / \mathrm{kg} \cdot{ }^{\circ} \mathrm{C}\right)$, and $k\left(\mathrm{~W} / \mathrm{m} \cdot{ }^{\circ} \mathrm{C}\right)$ are the density, the specific heat, and the thermal conductivity of the tissues, respectively. $Q(\mathrm{~W} / \mathrm{kg})$ is the metabolic heat generation rate; $S$ $(\mathrm{W} / \mathrm{kg})$ is the SAR due to EMF exposure; $\omega\left(\mathrm{m}^{3} / \mathrm{kg} \cdot \mathrm{s}\right)$ is the volumetric blood perfusion rate; and $\rho_{b}\left(\mathrm{~kg} / \mathrm{m}^{3}\right), c_{b}\left(\mathrm{~J} / \mathrm{kg} \cdot{ }^{\circ} \mathrm{C}\right)$, and $T_{b}\left({ }^{\circ} \mathrm{C}\right)$ are the density, the specific heat, and the temperature of blood, respectively.

When the goal of the simulation is to obtain the temperature increase $\left(T_{\text {incr }}\right)$ due to SAR exposure and such increase is expected to be small $\left(<1^{\circ} \mathrm{C}\right)$, some parameters and quantities can be considered time and temperature independent. These consist of: the tissue parameters $\left(\rho, c, k, \omega, Q, T_{b}\right)$, the parameters necessary to define boundary conditions [i.e., the heat transfer coefficient, due to convection cooling through air contact $\left.h\left(\mathrm{~W} / \mathrm{m}^{2}{ }^{\circ} \mathrm{C}\right)\right]$, the temperature outside the boundary, and the heat flux due to perspiration. Under this hypothesis, applying (1) twice, i.e., once with the exposed condition with SAR distribution $S$ and once for the unexposed condition $(S=0)$ and subtracting one from the other, one can obtain common terms, which cancel out. These include the term linked to metabolic heat $\rho Q$ and the one linked to the fixed blood temperature $T_{b}$, $\rho_{b} c_{b} \omega T_{b}$ (for further details on this approximation see [13]). Therefore, the previous equation in a more simplified version becomes

$$
\rho c \frac{\partial T}{\partial t}=\nabla \cdot(k \nabla T)+\rho Q+\rho S-\rho_{b} c_{b} \rho \omega\left(T-T_{b}\right) .
$$

This formulation is applied in this study, assuming that the temperature increase due to the SAR distributions generated by the exposure to a UHF RFID antenna with 1-W output power is expected to be less than $1{ }^{\circ} \mathrm{C}$, even for long time exposure. This assumption is supported by extending the current case, on a preliminary basis, the results of the studies [29]-[31], which have evaluated the temperature increase in the head, due to the exposure to a mobile phone antenna at $900 \mathrm{MHz}$.

Temperature rise was calculated for each exposure scenario both at the steady state (by assuming that the derivative of $T_{\text {incr }}$ over the time equals to zero in (2)) and as a function of time (considering a simulation time exposure of $3 \mathrm{~h}$ as suggested in [12]) to get information about the transient effects during the time of application of the exposure.

In the following, the exposure scenarios used in [24] will be referred as "seven months" R1 (or R2 or R3) and "nine months" $\mathrm{R} 1$ (or R2 or R3) for the seven months and nine months of GA, respectively, where R1, R2, and R3 are shown in Fig. 2. To allow the solution of (2), additional conditions have to be 


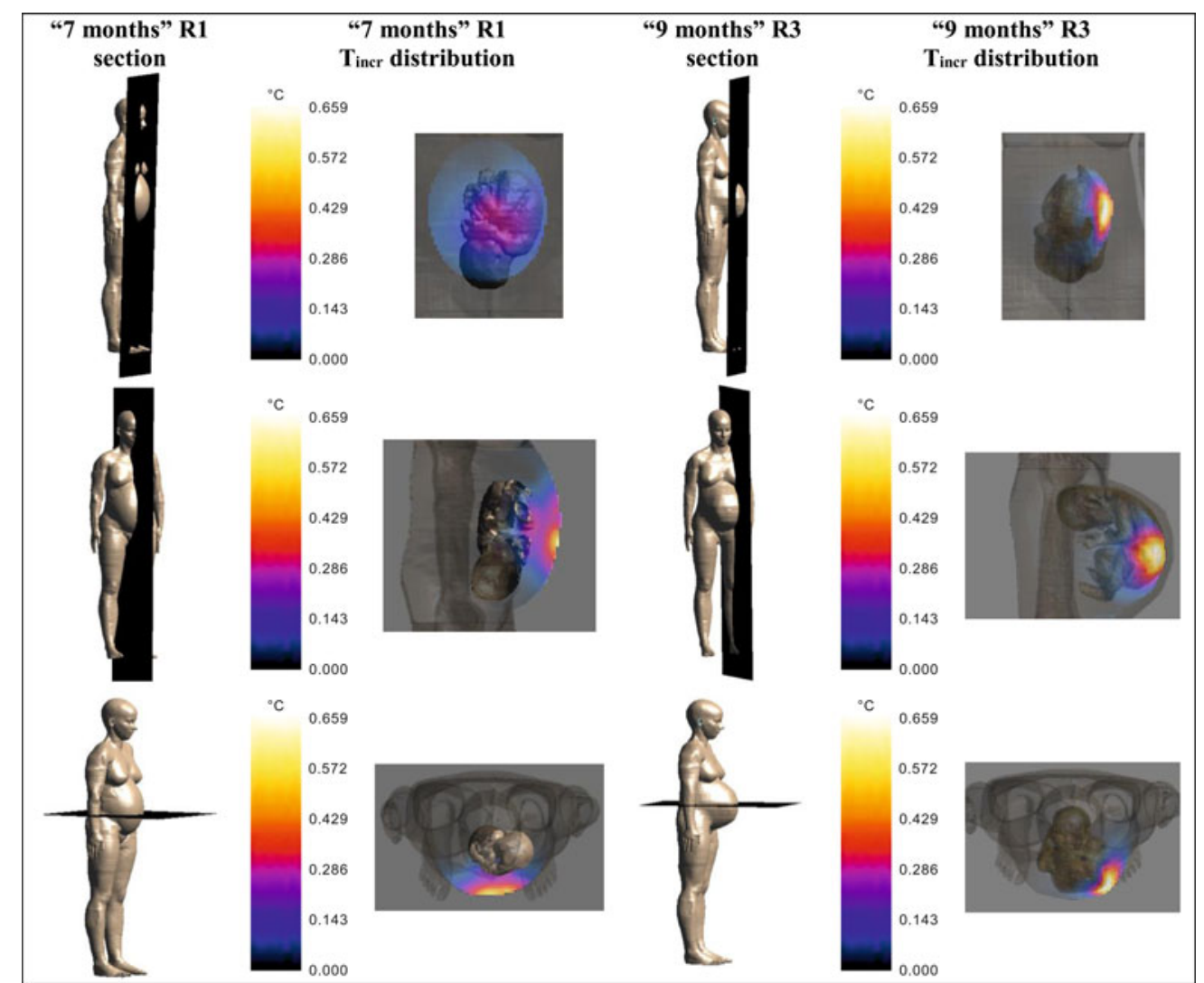

Fig. 3. $T_{\text {incr }}$ distributions at the steady -state for "seven months" R1 exposure (left) and "nine months" R3 exposure" (right) on coronal (first row), sagittal (second row), and transversal (third row) planes where maximum value of t $T_{\mathrm{incr}}$ in fetus was found. Scaling bars are clamped to the maximum found in the body fetus in the corresponding exposure scenario (see Table II). In each slice, the fetus model is superimposed to allow the reader understand its body position with respect to the temperature distributions.

considered at the boundaries of the simulation domain. Because of the materials at the interfaces of the boundaries, three types of boundary conditions were applied, as proposed by [13].

The first one is at the interfaces of tissues with air, where the following mixed boundary conditions were applied:

$$
k \frac{\partial T_{\text {incr }}}{\partial n}+h T_{\text {incr }}=0
$$

where $h$ is the heat transfer coefficient, and the derivative of $T_{\text {incr }}$ along the unitary vector $n$ is directed normally to surface of the interface. $h$ was set to $h_{\text {skin-air }}=8 \mathrm{~W} /\left(\mathrm{m}^{2} \cdot \mathrm{K}\right)$ at the interface between the maternal skin and the air, whereas between the maternal cornea and the air, it was set to $h_{\text {cornea-air }}$ $=20 \mathrm{~W} /\left(\mathrm{m}^{2} \cdot \mathrm{K}\right)$; and between the lung and the internal air with $h_{\text {lung-air }}=50 \mathrm{~W} /\left(\mathrm{m}^{2} \cdot \mathrm{K}\right)[26]$.

The second one is the adiabatic Neumann boundary condition, which was applied at the interface between maternal tissues and some air-filled cavities (i.e., internal air, bronchi lumen, esophagus lumen, pharynx, and trachea lumen)

$$
k \frac{\partial T_{\text {incr }}}{\partial n}=0
$$

The third one is the Dirichlet boundary condition

$$
T_{\text {incr }}=0
$$

applied at the interface between blood (i.e., artery, veins, and umbilical cord) and every tissue perfused by blood (all the tissues except air tissues, maternal and fetal CSF, maternal and fetal humor vitreous, amniotic fluid, teeth, stomach lumen, and small intestine lumen).

The nonuniform mesh in the thermal and electromagnetic simulations was kept the same as generated by the finitedifference time-domain (FDTD) algorithm [24], with a minimum step of $0.1 \mathrm{~mm}$ over the source and the skin thin layer and a maximum step of $4 \mathrm{~mm}$ in the background.

\section{Thermal Parameters}

The dielectric properties and the density of the tissues of the woman models are the same assigned in the previous paper [24]. However, the thermal simulations require estimation of the value of the thermal parameters of the tissues under investigation (i.e., $k, c, c b, \omega)$. The thermal parameters of the tissues of the woman are taken from [13], with the exception of the values of the amniotic fluid and of the placenta which were taken from [32], and of the umbilical cord, whose properties are considered the same as for the blood. Thermal properties of fetal tissues considered here are equivalent to the ones used for the corresponding adult tissues.

\section{RESULTS}

Fig. 3 shows some examples of the $T_{\text {incr }}$ distributions for both "seven months" R1 and "nine months" R3 cases on the 
TABLE III

Mean and Maximum of the Temperature Increase Distribution at the Steady State Calculated Over Some Maternal Tissues of the Two PREGNANT WOMEN IN COMPARISON WITH THE NONPREGNANT WOMAN IN THE SAME EXPOSURE SCENARIO

\begin{tabular}{|c|c|c|c|c|c|c|c|c|}
\hline \multirow[t]{2}{*}{ Tissue } & \multicolumn{2}{|c|}{ "7 months" R1 } & \multicolumn{2}{|c|}{ "Ella" R1 } & \multicolumn{2}{|c|}{ "9 months" R3 } & \multicolumn{2}{|c|}{ "Ella" R3 } \\
\hline & $\begin{array}{c}\text { Mean } \mathrm{T}_{\text {incr }} \\
{\left[{ }^{\circ} \mathrm{C}\right]}\end{array}$ & $\begin{array}{c}\text { Maximum } \\
\mathrm{T}_{\text {incr }} \\
{\left[{ }^{\circ} \mathrm{C}\right]} \\
\end{array}$ & $\begin{array}{c}\text { Mean } \mathrm{T}_{\text {incr }} \\
{\left[{ }^{\circ} \mathrm{C}\right]}\end{array}$ & $\begin{array}{c}\text { Maximum } \\
\mathrm{T}_{\text {incr }} \\
{\left[{ }^{\circ} \mathrm{C}\right]} \\
\end{array}$ & $\begin{array}{c}\text { Mean } \mathrm{T}_{\text {incr }} \\
{\left[{ }^{\circ} \mathrm{C}\right]}\end{array}$ & $\begin{array}{c}\text { Maximum } \\
\mathrm{T}_{\text {incr }} \\
{\left[{ }^{\circ} \mathrm{C}\right]} \\
\end{array}$ & $\begin{array}{c}\text { Mean } \mathrm{T}_{\text {incr }} \\
{\left[{ }^{\circ} \mathrm{C}\right]}\end{array}$ & $\begin{array}{c}\text { Maximum } \\
\mathrm{T}_{\text {incr }} \\
{\left[{ }^{\circ} \mathrm{C}\right]}\end{array}$ \\
\hline Bone & 0.001 & 0.021 & 0.005 & 0.149 & 0.001 & 0.021 & 0.004 & 0.113 \\
\hline Connective_tissue & 0.001 & 0.024 & 0.005 & 0.165 & 0.001 & 0.023 & 0.003 & 0.247 \\
\hline Fat & 0.012 & 0.442 & 0.007 & 0.170 & 0.001 & 0.566 & 0.006 & 0.267 \\
\hline Large_intestine & 0.001 & 0.013 & 0.006 & 0.061 & 0.001 & 0.009 & $<0.001$ & 0.002 \\
\hline Muscle & 0.001 & 0.243 & 0.005 & 0.193 & 0.001 & 0.029 & 0.007 & 0.304 \\
\hline SAT & 0.007 & 0.490 & 0.003 & 0.160 & 0.004 & 0.590 & 0.004 & 0.237 \\
\hline Skin & 0.006 & 0.537 & 0.004 & 0.180 & 0.004 & 0.523 & 0.003 & 0.236 \\
\hline Small_intestine & 0.001 & 0.025 & 0.003 & 0.040 & $<0.001$ & 0.004 & $<0.001$ & 0.003 \\
\hline Uterus & 0.027 & 0.242 & 0.002 & 0.003 & 0.031 & 0.664 & $<0.001$ & $<0.001$ \\
\hline Whole Body & 0.005 & $\begin{array}{l}0.537 \\
\text { (skin) }\end{array}$ & 0.004 & $\begin{array}{c}0.193 \\
\text { (muscle) }\end{array}$ & 0.004 & $\begin{array}{c}0.715 \\
\text { (amniotic } \\
\text { fluid) }\end{array}$ & 0.004 & $\begin{array}{c}0.304 \\
\text { (muscle) }\end{array}$ \\
\hline
\end{tabular}

coronal (first row), sagittal (second row), and transversal (third row) planes. The three views for each pregnant woman model give information about the spatial distribution of $T_{\text {incr }}$ in the womb.

High values of $T_{\mathrm{incr}}$ are encountered not only in the fetus body, but also in the amniotic fluid. This is particularly evident in the "seven months" case, in the sagittal and transversal views. Table III shows the $T_{\mathrm{incr}}$ in some tissues of the two pregnant women wombs in comparison with the ones calculated over the nonpregnant women for the same exposure conditions (R1 and R3). Tissues in brackets in the last row represent the location of the peak $T_{\text {incr }}$ over the whole body. The most remarkable differences in terms of maxima $T_{\mathrm{incr}}$ were found in the uterus (few $\mathrm{m}{ }^{\circ} \mathrm{C}$ versus almost $0.7{ }^{\circ} \mathrm{C}$ with respect to nonpregnant and nine-month pregnant woman, respectively), which is also the most deformed tissue. However, as expected, the pregnant women tissues closest to the highly conductive and highly heated fetus and the amniotic fluid (such as fat, subcutaneous adipose tissue-SAT, skin) are more heated (see the columns of the maxima $T_{\text {incr }}$ ) than the corresponding tissues in the nonpregnant women, whereas the tissues behind the womb (such as bone and connective tissue) are less heated because of the major distance from the source.

Table IV summarizes the $T_{\text {incr }}$ calculated in the body of the fetus and in two other tissues in contact with the fetus itself, i.e., the amniotic fluid and the placenta. For the fetus and the amniotic fluid, the maxima of the temperature increase were found in the "nine months" R3 (maximum increase of about $0.7^{\circ} \mathrm{C}$ in the amniotic fluid and $0.65^{\circ} \mathrm{C}$ in the fetus).

Similar values, although slightly smaller, were found in the "nine months" R1. On the contrary, the temperature increases are lower (more than 50\% lower) for the "nine months" R2 and "seven months" R1, R2, and R3 exposure scenarios. The maximum $T_{\text {incr }}$ in the placenta is negligible with respect to the other two tissues, for both pregnant women and for all the exposure scenarios. The mean values in the three tissues are dramatically lower, with a maximum mean $T_{\text {incr }}$ in the amniotic fluid of $0.037^{\circ} \mathrm{C}$ for "nine months" $\mathrm{R} 2$. In the fetus, the mean $T_{\text {incr }}$ reaches a maximum value of $0.25^{\circ} \mathrm{C}$ for the "nine months" R1.

Fig. 4 shows the histogram of the $T_{\text {incr }}$ in the body of the fetus for the two pregnant women and the three exposure scenarios, in terms of the body volume fractions. In each panel, $T_{\mathrm{incr}}$ is shown
TABLE IV

Mean AND MaXimum of the Temperature InCREASE Distribution at THE Steady State Due to the Three Exposure Scenarios R1, R2, R3 Calculated Over the Fetus, Amniotic Fluid, and Placenta

\begin{tabular}{cccc}
\hline Exposure & Tissue & $\begin{array}{c}\text { Mean } \\
T_{\text {incr }} \\
\text { Scenario }\end{array}$ & $\begin{array}{c}\text { Maximum } \\
T_{\text {incr }}\end{array}$ \\
& & {$\left[{ }^{\circ}\right]$} & {$\left[{ }^{\circ} \mathrm{C}\right]$} \\
\hline "7 months" & Fetus & 0.015 & 0.204 \\
RI & Amniotic fluid & 0.036 & 0.245 \\
& Placenta & $<0.001$ & 0.006 \\
"7 months" & Fetus & 0.008 & 0.091 \\
R2 & Amniotic fluid & 0.015 & 0.102 \\
& Placenta & $<0.001$ & 0.031 \\
"7 months" & Fetus & 0.010 & 0.162 \\
R3 & Amniotic fluid & 0.017 & 0.181 \\
& Placenta & $<0.001$ & 0.040 \\
"9 months" & Fetus & 0.025 & 0.468 \\
RI & Amniotic fluid & 0.026 & 0.617 \\
& Placenta & $<0.001$ & 0.012 \\
"9 months" & Fetus & 0.012 & 0.182 \\
R2 & Amniotic fluid & 0.037 & 0.325 \\
& Placenta & $<0.001$ & 0.010 \\
"9 months" & Fetus & 0.020 & 0.659 \\
R3 & Amniotic fluid & 0.025 & 0.715 \\
& Placenta & $<0.001$ & 0.010 \\
\hline
\end{tabular}

as normalized with respect to its maximum in the corresponding exposure scenario, as shown in Table IV. Most of the fetal body volume is affected by a very low increase in temperature for both pregnant women and for all the three exposure scenarios. Indeed, at minimum, the $70 \%$ of the fetal body volume is affected by a $T_{\text {incr }}$ lower than one-tenth of its maximum in the tissues across all the exposure scenarios and women models.

The uncertainty budget on the maximum $T_{\text {incr }}$ in the body of the fetus due to the variation of the mass of the fetal tissues was equal to $0.2 \%$ for "seven months" R1 and $0.01 \%$ for the "nine months" R3.

Tables V and VI show the mean and the maximum values of $T_{\text {incr }}$ distribution at the steady state for each fetal tissue of the "seven months" and "nine months" models, respectively.

Disregarding the exposure scenario, the maxima $T_{\text {incr }}$ are located in superficial tissues (skin, SAT, fat), followed by the muscle and the bone, for both seven- and nine-month GA models. However, one should note that the mean values per tissue are extremely lower than the corresponding maxima. Fig. 5 shows the temporal pattern of $T_{\text {incr }}$ estimated at the point of the maximum at the steady state in the body of the fetus (see Tables V 
"7 months" R1

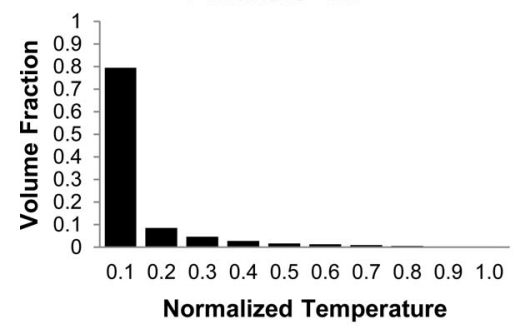

"9 months" R1

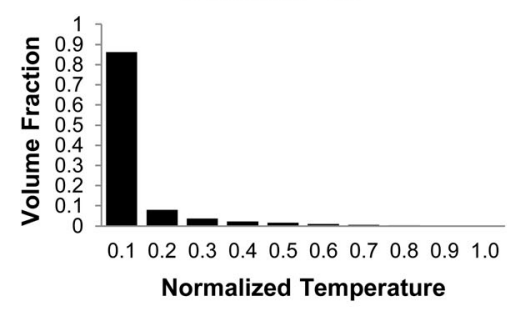

"7 months" R2

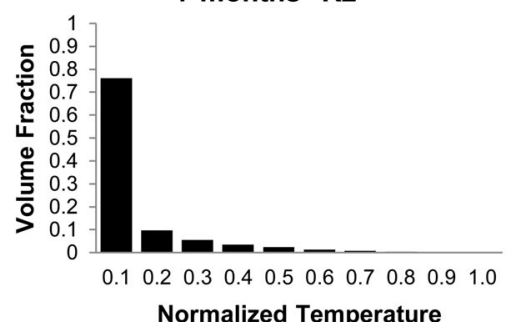

"9 months" R2

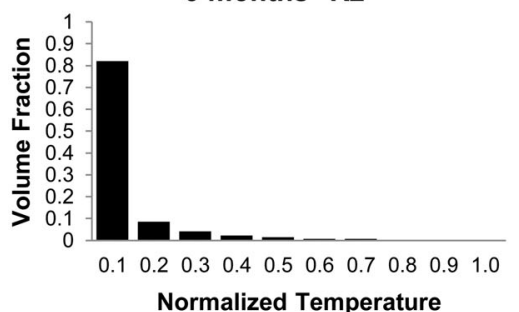

"7 months" R3

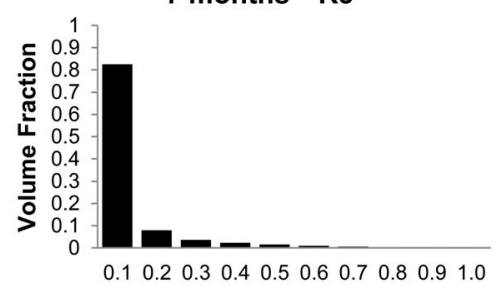

Normalized Temperature

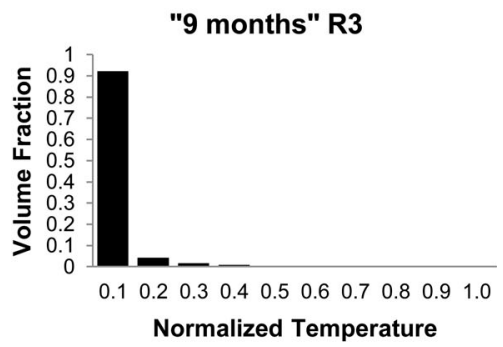

Fig. 4. Histograms of the $T_{\mathrm{incr}}$ distribution at the steady state in the body of the fetus for the two pregnant women and the three exposure scenarios, normalized with respect to the maximum values found in the body fetus in the corresponding exposure scenario (see Table IV).

TABLE V

MEAN AND MAXIMUM OF THE TEMPERATURE INCREASE Distribution AT THE Steady State Calculated Over Each Fetal Tissue of the "Seven MONTHS" FETUS EXPOSED TO THE UHF RFID

\begin{tabular}{|c|c|c|c|c|c|c|}
\hline \multirow[b]{2}{*}{ Tissue } & \multicolumn{2}{|c|}{ R1 } & \multicolumn{2}{|c|}{ R2 } & \multicolumn{2}{|c|}{ R3 } \\
\hline & $\begin{array}{c}\text { Mean } \\
\mathrm{T}_{\text {incr }} \\
{\left[{ }^{\circ} \mathrm{C}\right]}\end{array}$ & $\begin{array}{c}\text { Max } \\
T_{\text {incr }} \\
{\left[{ }^{\circ} \mathrm{C}\right]}\end{array}$ & $\begin{array}{c}\text { Mean } \\
\mathrm{T}_{\text {incr }} \\
{\left[{ }^{\circ} \mathrm{C}\right]}\end{array}$ & $\begin{array}{l}\text { Max } \\
\mathrm{T}_{\text {incr }} \\
{\left[{ }^{\circ} \mathrm{C}\right]}\end{array}$ & $\begin{array}{c}\text { Mean } \\
\mathrm{T}_{\text {incr }} \\
{\left[{ }^{\circ} \mathrm{C}\right]}\end{array}$ & $\begin{array}{l}\mathrm{Max} \\
\mathrm{T}_{\text {incr }} \\
{\left[{ }^{\circ} \mathrm{C}\right]}\end{array}$ \\
\hline Bladder & 0.005 & 0.014 & 0.003 & 0.006 & 0.002 & 0.005 \\
\hline Bone & 0.013 & 0.131 & 0.006 & 0.047 & 0.007 & 0.074 \\
\hline $\begin{array}{l}\text { Brain white } \\
\text { matter }\end{array}$ & 0.001 & 0.019 & 0.001 & 0.010 & 0.001 & 0.012 \\
\hline Eye & 0.022 & 0.049 & 0.005 & 0.014 & 0.005 & 0.013 \\
\hline Fat & 0.020 & 0.175 & 0.010 & 0.076 & 0.014 & 0.137 \\
\hline Gallbladder & 0.004 & 0.006 & 0.002 & 0.004 & 0.004 & 0.005 \\
\hline Heart & 0.003 & 0.014 & 0.001 & 0.006 & 0.003 & 0.011 \\
\hline Intestine & 0.001 & 0.013 & 0.001 & 0.009 & 0.001 & 0.014 \\
\hline Kidney & 0.002 & 0.014 & 0.002 & 0.027 & 0.004 & 0.037 \\
\hline Liver & 0.004 & 0.035 & 0.002 & 0.022 & 0.004 & 0.038 \\
\hline Lung & 0.005 & 0.063 & 0.006 & 0.028 & 0.010 & 0.059 \\
\hline Muscle & 0.022 & 0.148 & 0.009 & 0.053 & 0.010 & 0.082 \\
\hline SAT & 0.032 & 0.200 & 0.015 & 0.084 & 0.019 & 0.151 \\
\hline Skin & 0.027 & 0.204 & 0.014 & 0.091 & 0.019 & 0.162 \\
\hline Spinal cord & 0.002 & 0.008 & 0.005 & 0.009 & 0.006 & 0.011 \\
\hline Spleen & 0.000 & 0.001 & 0.001 & 0.002 & 0.001 & 0.002 \\
\hline Stomach & 0.001 & 0.002 & 0.001 & 0.001 & 0.001 & 0.002 \\
\hline
\end{tabular}

and VI for the corresponding tissues). Considering $T_{\text {incr }}$ as the response of the biological system to the step input represented by the electromagnetic field, one can consider the time constant $\tau$ as the parameter characterizing the response itself. $\tau$ is typically defined as the time in which the system response reaches about the $62 \%$ of its steady-state value. In general, $\tau$ is lower for the seven-month GA cases than for the nine-month GA. In Fig. 5, $\tau$ varies between $10 \mathrm{~min}$ ("seven months" R3) and $48 \mathrm{~min}$ ("nine months" R2).

Additional quantitative information about the time course of $T_{\text {incr }}$ can be found in Table VII, showing the percentage of the steady state reached by $T_{\text {incr }}$ as a function of time. After $60 \mathrm{~min}$ of exposure, $T_{\text {incr }}$ reaches at least the $90 \%$ of its corresponding value at the steady state for all the exposure scenarios, except
TABLE VI

MEAN AND MAXIMUM OF THE TEMPERATURE INCREASE DistribUTION AT THE Steady State Calculated Over Each Fetal Tissue of the "Nine MONTHS" FETUS EXPOSED TO UHF RFID

\begin{tabular}{|c|c|c|c|c|c|c|}
\hline \multirow[b]{2}{*}{ Tissue } & \multicolumn{2}{|c|}{$\mathrm{R} 1$} & \multicolumn{2}{|c|}{$\mathrm{R} 2$} & \multicolumn{2}{|c|}{ R3 } \\
\hline & $\begin{array}{c}\text { Mean } \\
\mathrm{T}_{\text {incr }} \\
{\left[{ }^{\circ} \mathrm{C}\right]}\end{array}$ & $\begin{array}{c}\operatorname{Max} \\
\mathrm{T}_{\text {incr }} \\
{\left[{ }^{\circ} \mathrm{C}\right]}\end{array}$ & $\begin{array}{c}\text { Mean } \\
\mathrm{T}_{\text {incr }} \\
{\left[{ }^{\circ} \mathrm{C}\right]}\end{array}$ & $\begin{array}{c}\text { Max } \\
\mathrm{T}_{\text {incr }} \\
{\left[{ }^{\circ} \mathrm{C}\right]}\end{array}$ & $\begin{array}{c}\text { Mean } \\
\mathrm{T}_{\text {incr }} \\
{\left[{ }^{\circ} \mathrm{C}\right]}\end{array}$ & $\begin{array}{c}\text { Max } \\
\mathrm{T}_{\text {incr }} \\
{\left[{ }^{\circ} \mathrm{C}\right]}\end{array}$ \\
\hline $\begin{array}{c}\text { Adrenal } \\
\text { Gland }\end{array}$ & 0.008 & 0.027 & 0.001 & 0.001 & 0.004 & 0.013 \\
\hline Bladder & 0.039 & 0.081 & 0.008 & 0.015 & 0.023 & 0.059 \\
\hline Bone & 0.021 & 0.303 & 0.007 & 0.095 & 0.012 & 0.164 \\
\hline $\begin{array}{c}\text { Brain white } \\
\text { matter }\end{array}$ & 0.000 & 0.001 & 0.000 & 0.003 & 0.000 & 0.002 \\
\hline $\mathrm{CSF}$ & 0.000 & 0.002 & 0.001 & 0.005 & 0.001 & 0.003 \\
\hline Esophagus & 0.002 & 0.002 & 0.002 & 0.002 & 0.003 & 0.005 \\
\hline Eye Lens & 0.000 & 0.000 & 0.000 & 0.000 & 0.001 & 0.001 \\
\hline $\begin{array}{c}\text { Eye } \\
\text { Vitreous }\end{array}$ & 0.001 & 0.001 & 0.003 & 0.008 & 0.001 & 0.003 \\
\hline Fat & 0.033 & 0.383 & 0.015 & 0.135 & 0.029 & 0.525 \\
\hline Gallbladder & 0.008 & 0.013 & 0.000 & 0.001 & 0.002 & 0.005 \\
\hline Heart & 0.000 & 0.001 & 0.000 & 0.003 & 0.001 & 0.003 \\
\hline Kidney & 0.005 & 0.031 & 0.001 & 0.002 & 0.003 & 0.021 \\
\hline Liver & 0.003 & 0.045 & 0.000 & 0.004 & 0.001 & 0.006 \\
\hline Lung & 0.002 & 0.018 & 0.001 & 0.011 & 0.002 & 0.013 \\
\hline Muscle & 0.028 & 0.385 & 0.012 & 0.131 & 0.020 & 0.281 \\
\hline Ovary & 0.016 & 0.018 & 0.004 & 0.005 & 0.019 & 0.037 \\
\hline Pancreas & 0.004 & 0.004 & 0.001 & 0.003 & 0.004 & 0.009 \\
\hline SAT & 0.035 & 0.468 & 0.020 & 0.170 & 0.034 & 0.587 \\
\hline Skin & 0.036 & 0.464 & 0.019 & 0.182 & 0.030 & 0.659 \\
\hline $\begin{array}{c}\text { Small } \\
\text { Intestine }\end{array}$ & 0.007 & 0.084 & 0.002 & 0.020 & 0.006 & 0.085 \\
\hline Spinal cord & 0.063 & 0.201 & 0.003 & 0.014 & 0.020 & 0.064 \\
\hline Spleen & 0.004 & 0.014 & 0.005 & 0.019 & 0.014 & 0.052 \\
\hline Stomach & 0.002 & 0.003 & 0.004 & 0.013 & 0.008 & 0.027 \\
\hline Thymus & 0.000 & 0.000 & 0.000 & 0.001 & 0.000 & 0.001 \\
\hline $\begin{array}{l}\text { Thyroid } \\
\text { gland }\end{array}$ & 0.000 & 0.000 & 0.000 & 0.000 & 0.000 & 0.000 \\
\hline Uterus & 0.054 & 0.069 & 0.008 & 0.011 & 0.024 & 0.032 \\
\hline
\end{tabular}

in the "nine months" R2. After $120 \mathrm{~min}$, the steady-state value is approximately achieved in all cases but in the "nine months" R2. 


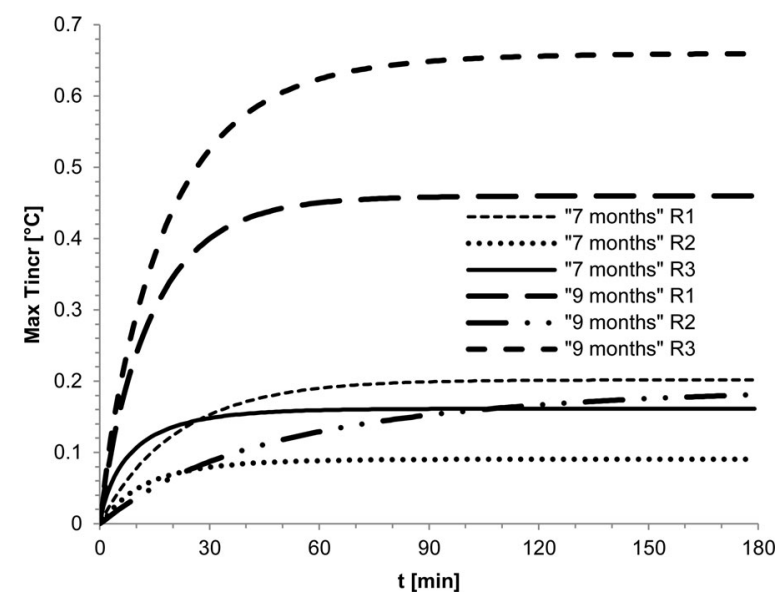

Fig. 5. Maximum $T_{\text {incr }}$ time courses over the whole fetus models for the six exposure scenarios investigated.

TABLE VII

DIFFERENCE (IN TERMS OF PERCENTAGE) OF THE "MAXIMUM $T_{\text {incr }}$ " Calculated in the Fetus at DifFerent Time (FIRST LeFt Column), with Respect to the "MaXimum $T_{\text {incr }}$ " at the Steady State

\begin{tabular}{r|rrr|rrr}
\hline $\begin{array}{c}\text { Time } \\
\text { (min) }\end{array}$ & \multicolumn{5}{c}{ \% of Steady State } \\
\hline & "7 months" & & \multicolumn{3}{c}{ "9 months" } \\
& R1 & R2 & R3 & R1 & R2 & R3 \\
\hline 1 & 4.8 & 5.3 & 15.2 & 8.4 & 2.1 & 6.8 \\
6 & 25.2 & 36.6 & 51.4 & 36.1 & 12.5 & 31.0 \\
10 & 38.2 & 53.2 & 65.7 & 51.1 & 20.1 & 44.5 \\
60 & 93.2 & 97.1 & 98.0 & 96.2 & 71.0 & 94.7 \\
120 & 98.6 & 99.2 & 99.3 & 98.1 & 91.5 & 99.5 \\
180 & 98.9 & 99.2 & 99.3 & 98.2 & 99.2 & 99.9 \\
\hline
\end{tabular}

\section{DISCUSSION AND CONCLUSION}

As discussed in Section I, the limited capability of the fetus to regulate its own temperature makes the fetal temperature assessment an urgent topic to be addressed when the pregnant woman is exposed to radio frequencies. This paper starts from a previous assessment of electromagnetic power absorption [24] due to UHF RFID reader. Some potentially crucial exposure scenarios for the fetus exposed to a UHF RFID reader antenna with 1-W output power were found there. To this purpose, this study addresses the assessment of the temperature increase at fetal tissue level in those scenarios.

Before entering in the discussion, one should bear in mind that the results (as in [24]) are presented by considering a duty cycle of $100 \%$ to account for the worst-case RFID practical transmission mode. Therefore, for different duty cycles, the maximum temperature rise will be a fraction of the reported ones here. Moreover, as mentioned before, the data presented here were obtained considering the reader output power of $1 \mathrm{~W}$, whereas the typical UHF RFID output powers of the antenna usually are in the range $25 \mathrm{~mW}-1.9 \mathrm{~W}$ [33], [34], while the maximum allowed ERP in Europe is of $2 \mathrm{~W}$ [35]. However, since the reader output power is approximately linear with SAR and with temperature increase at the thermally steady state [36], [37], it is possible to scale the values of the $T_{\mathrm{incr}}$ at the steady state found in this study to any output power, once known the one relative to the device under investigation.

First of all, the "nine months" fetus shows higher temperature increase with respect to the "seven months" fetus. This is certainly due to the higher psSAR $10 \mathrm{~g}$ experienced by the "nine months" fetus, according to [24] (see Table II). As an additional explanation, one should take into account the presence of a larger volume of the amniotic fluid (which has high electric and thermal conductivities and, as shown in Table IV, even higher temperature increase than the fetus itself) in the "nine months" than in the "seven months" fetus. This study indicates that UHF RFID exposure of the whole fetus results in localized heating of the fetal tissues up to a maximum of $0.66^{\circ} \mathrm{C}$ at the steady state in the nine-month fetus and of $0.20^{\circ} \mathrm{C}$ in the seven months one. However, the largest increase is in the amniotic fluid, where it reaches $0.72{ }^{\circ} \mathrm{C}$ and $0.25^{\circ} \mathrm{C}$, respectively. All these values are, however, still lower than the threshold of $1{ }^{\circ} \mathrm{C}$ indicated by the ICNIRP guidelines [4] as limits for the temperature increase in case of whole-body exposure and used by some authors [13] as threshold for localized exposure.

On the contrary, the placenta is not affected by the exposure in terms of tissue heating. The reader position R1 and R3 (in front of and in the oblique direction with respect to the belly of the pregnant woman, respectively) are the exposure scenarios resulting in the highest increase of temperature for both mother models. The most superficial tissues and/or those ones close to the amniotic fluid (e.g., skin, SAT, fat, muscle, bone) experience the highest increase in temperature. These maxima, however, are highly localized (i.e., confined in a small volume) in the tissues, especially in the fetus body, where between $70 \%$ and $90 \%$ of the volume is experiencing an increase of the temperature of about one-tenth of the maxima. The time to reach $90 \%$ of the steady state of the temperature increase is about $60 \mathrm{~min}$ for all cases but one exposure scenario of "nine months" fetus. This indicates that the exposure should be continued for a long time to result in a sensible increase of the temperature. However, this cannot be "a priori" excluded in the case of exposure to a UHF RFID reader addressed in this study, considering that, in many practical applications, the device is set to emit continuously, in search of an RFID tag.

As a final remark, the shortcomings and limitations intrinsic in any simulation based on computational study should always be considered in the interpretation of the results. These can be essentially grouped into two main categories:

1) computational errors, such as discretization error, staircase effect, choice of boundary condition, as well as of SAR calculation algorithm;

2) modeling uncertainties, i.e., variations in results caused by different choices, simplifications, and approximations made according to the judgment of the user, or by the solver software. They include: the accuracy of the human body and source geometrical modeling, the choice of dielectric and thermal properties, and the positioning of the source.

Specifically, the issue of the discretization errors has been investigated in the past [38]-[41]. Among these studies, a mesh resolution smaller than $2 \mathrm{~mm}$ like the one used in this study has 
been demonstrated to change the results up to a maximum of $10 \%$ in both wbSAR and $\mathrm{psSAR}_{10 \mathrm{~g}}$ for frequencies lower than $1 \mathrm{GHz}$.

The staircase effect could be of great impact at the outer boundary of the pregnant women, but it is less important over the (internal) fetal tissues [42]. The reflection error due to the perfectly matched layer absorbing boundary conditions was surely avoided [43]-[45] by keeping a distance of more than one wavelength (more than $30 \mathrm{~cm}$ ) between the source and the boundaries of the computational domain. Again, the differences among different SAR calculation algorithms are generally under $5 \%$ for frequency below $1 \mathrm{GHz}$ [46].

As to the modeling uncertainty sources, the ones that most affect the reliability of the results in case of near-field exposure (handset sources) are the positioning of the source [47] and the variability of the model [48]. These two issues have been widely studied in terms of psSAR $10 \mathrm{~g}$ variation in the previous work [24] by varying the RFID reader position around the pregnant women wombs and by comparing the exposure over different anatomical models in the same exposure scenario.

Moreover, in this study, the reliability of the fetus model was evaluated through a specific assessment. The uncertainty of the maximum $T_{\text {incr }}$ over the whole fetuses was found to be less than $1 \%$ in both cases of pregnant models, thus demonstrating that the remarkable individual organ mass variations do not affect the results discussed here.

In addition to that, the most remarkable limitations in the body modeling not tackled here are:

1) To neglect the contribution given by the very thin vessels (e.g., in the umbilical cord and the placenta) to the cooling of the fetal tissues. This should better mimic the real heat exchange and would contribute to a more accurate temperature increase estimation [32]. However, inclusion of these vessels tends to decrease the temperature rise estimate, thus assuring that the results discussed here represent a conservative estimate of the temperature increase;

2) To disregard the possible change in fetal position within the uterus. This would affect the temperature distribution both from a global and tissue level point of view, even if the maximum levels as well as the average temperature increase over the fetus would be minimally affected by this issue.

As to the variation of dielectric and thermal properties, several authors have shown that it is unlikely to have a significant impact on the whole-body SAR and maximum psSAR [49]-[55]. However, the influence of modeling parameters on the correlated standard uncertainty of the peak temperature increase was discussed in [13], indicating that it is variable among different scenarios, but remains within the range $15 \%-30 \%$.

In conclusion, the exposure of a fetus to SAR levels generated by an RFID UHF reader results in a temperature increase which is not negligible, even though it is highly localized and is reached after significant exposure times. The GA also plays a role, with larger temperature increase for longer GA. This is confirmed by comparison with most of the tissues of the nonpregnant woman, particularly the uterus. As to possible effects on health, a more detailed analysis should be performed on the tissues involved and the relationship between their heating and the fetus health.

However, the results discussed here, even if affected by the uncertainty intrinsic in any modeling problem, indicate that practical measures to avoid overexposure and reduce the RF heat deposition of the fetus could be recommended. For the specific exposure condition studied here, these measures could include: 1) to keep the reader antenna at least $20 \mathrm{~cm}$ away from the pregnant women womb and 2) to reduce as much as possible the time of exposure.

\section{REFERENCES}

[1] K. Finkenzeller, RFID Handbook. Fundamentals and Applications in Contactless Smart Cards and Identification, 3rd ed. New York, NY, USA: Wiley, Jun. 2010

[2] L. Kheifets, M. Repacholi, R. Saunders, and E. Van Deventer, "The sensitivity of children to electromagnetic fields," Pediatrics, vol. 116, pp. e303e313, Aug. 2005

[3] C. Polk and E. Postow, Handbook of Biological Effects of Electromagnetic Fields, 2nd ed. Boca Raton, FL, USA: CRC Press, Dec. 1995.

[4] The International Commission on Non-Ionizing Radiation Protection, "Guidelines for limiting exposure to time-varying electric, magnetic, and electromagnetic fields (up to $300 \mathrm{GHz}$ )," Health Phys., vol. 74, pp. 494 522, Apr. 1998

[5] J. W. Hand, Y. Li, E. L. Thomas, M. A. Rutherford, and J. V. Hajnal, "Prediction of specific absorption rate in mother and fetus associated with MRI examinations during pregnancy," Magn. Reson. Med., vol. 55, pp. 883-893, Apr. 2006

[6] M. Pediaditis, N. Leitgeb, and R. Cech, "RF-EMF exposure of fetus and mother during magnetic resonance imaging," Phys. Med. Biol., vol. 53 , pp. 7187-7195, Dec. 2008

[7] M. Murbach, E. Cabot, E. Neufeld, M.C. Gosselin, A. Christ, K.P. Pruessmann, and N. Kuster, "Local SAR enhancements in anatomically correct children and adult models as a function of position within 1.5 T MR body coil," Prog. Biophys. Mol. Biol., vol. 107, pp. 428-433, Dec. 2011

[8] W. Kainz, D. D. Chan, J. P. Casamento, and H. I. Bassen, "Calculation of induced current densities and specific absorption rates (SAR) for pregnant women exposed to hand-held metal detectors," Phys. Med. Biol., vol. 48, pp. 2551-2560, Aug. 2003.

[9] P. J. Dimbylow, "SAR in the mother and foetus for RF plane wave irradiation," Phys. Med. Biol., vol. 52, pp. 3791-3802, Jul. 2007.

[10] T. Nagaoka, T. Togashi, K. Saito, M. Takahashi, K. Ito, and S. Watanabe, "An anatomically realistic whole-body pregnant-woman model and specific absorption rates for pregnant-woman exposure to electromagnetic plane waves from $10 \mathrm{MHz}$ to $2 \mathrm{GHz}$," Phys. Med. Biol., vol. 52, pp. 67316745, Nov. 2007

[11] C. M. Collins, W. Liu, J. Wang, R. Gruetter, J. T. Vaughan, K. Ugurbil, and M. B. Smith, "Temperature and SAR calculations for a human head within volume and surface coils at 64 and $300 \mathrm{MHz}$," J. Mag. Reson. Imag., vol. 19, pp. 650-656, May 2004.

[12] A. Hirata, T. Asano, and O. Fujiwara, "FDTD analysis of body-core temperature elevation in children and adults for whole-body exposure," Phys. Med. Biol., vol. 53, pp. 5223-5238, Sep. 2008.

[13] J. F. Bakker, M. M. Paulides, E. Neufeld, A. Christ, N. Kuster, and G. C. Van Rhoon, "Children and adults exposed to electromagnetic fields at the ICNIRP reference levels: Theoretical assessment of the induced peak temperature increase," Phys. Med. Biol., vol. 56, pp. 4967-4989, Aug. 2011.

[14] A. Hirata, I. Laakso, T. Oizumim, R. Hanatani, K. H Chan, and J. Wiart, "The relationship between specific absorption rate and temperature elevation in anatomically based human body models for plane wave exposure from $30 \mathrm{MHz}$ to $6 \mathrm{GHz}$," Phys. Med. Biol., vol. 58, pp. 903-921, Jan. 2013

[15] D. A. Nelson, A. R. Curran, H. A. Nyberg, E. A. Martilla, P. A. Mason, and J. M. Ziriax, "High-resolution simulations of the thermophysiological effects of human exposure to $100 \mathrm{MHz}$ RF energy," Phys. Med. Biol., vol. 58, pp. 1947-1968, Mar. 2013

[16] D. Wu, S. Shamsi, J. Chen, and W. Kainz, "Evaluations of specific absorption rate and temperature increase within pregnant female models in magnetic resonance imaging birdcage coils," IEEE Trans. Microw. Theory Techn., vol. 54, no. 12, pp. 4472-4478, Dec. 2006. 
[17] J. W. Hand, Y. Li, and J. V. Hajnal, "Numerical study of RF exposure and the resulting temperature rise in the foetus during a magnetic resonance procedure," Phys. Med. Biol., vol. 55, pp. 913-930, Feb. 2010.

[18] S. Kikuchi, K. Saito, M. Takahashi, and K. Ito, "Temperature elevation in the fetus from electromagnetic exposure during magnetic resonance imaging," Phys. Med. Biol., vol. 55, pp. 2411-2426, Apr. 2010.

[19] H. J. Lee, J. S. Lee, J. K. Pack, H. D. Choi, N. Kim, S. H. Kim, and Y. S. Lee, "Lack of teratogenicity after combined exposure of pregnant mice to CDMA and WCDMA radiofrequency electromagnetic fields," Radiat. Res, vol. 172, pp. 648-652, Nov. 2009.

[20] R. L. McIntosh, L. Deppeler, M. Oliva, J. Parente, F. Tambuwala, S. Turner, D. Winship, and A. W. Wood, "Comparison of radiofrequency exposure of a mouse dam and foetuses at $900 \mathrm{MHz}$," Phys. Med. Biol., vol. 55, pp. N111-N122, Feb. 2010.

[21] H. H. Pennes, "Analysis of tissue and arterial blood temperature in the resting human forearm," J. Appl. Physiol., vol. 1, pp. 93-122, Aug. 1948.

[22] H. Asakura, "Fetal and neonatal thermoregulation," J. Nihon Med. Sch., vol. 71, pp. 360-370, Dec. 2004.

[23] M. C. Ziskin and J. Morrissey, "Thermal thresholds for teratogenicity, reproduction, and development," Int. J. Hyperthermia, vol. 27, pp. 374$387,2011$.

[24] S. Fiocchi, I. A. Markakis, P. Ravazzani, and T. Samaras, "SAR Exposure from UHF RFID reader in adult, child, pregnant woman and fetus anatomical models," Bioelectromagnetics, vol. 34, pp. 443-452, 2013.

[25] A. Christ, W. Kainz, E. G. Hahn, K. Honegger, M. Zefferer, E. Neufeld, W. Rascher, R. Janka, W. Bautz, J. Chen, B. Kiefer, P. Schmitt, H. P. Hollenbach, J. Shen, M. Oberle, D. Szczerba, A. Kam, J. W. Guag, and N. Kuster, "The Virtual Family-Development of surface-based anatomical models of two adults and two children for dosimetric simulations," Phys. Med. Biol., vol. 55, pp. N23-N38, Jan. 2010.

[26] A. Christ, R. Guldimann, B. Bühlmann, M. Zefferer, J. F. Bakker, G. C. Van Rhoon, and N. Kuster, "Exposure of the human body to professional and domestic induction cooktops compared to the basic restrictions," Bioelectromagnetics, vol. 33, pp. 695-705, Dec. 2012.

[27] International Commission on Radiological Protection, "Basic anatomical and physiological data for use in radiological protection: Reference values," Ann. ICRP, vol. 32, no. 3-4, pp. 31-52, 2002.

[28] SEMCAD X by SPEAG, version 14.4.0, Zurich, 2011. Available: www. speag.com

[29] J. Wang and O. Fujiwara, "FDTD computation of temperature rise in the human head for portable telephones," IEEE Trans. Microw. Theory Techn., vol. 47, no. 8, pp. 1528-1534, Aug. 1999.

[30] P. Bernardi, M. Cavagnaro, S. Pisa, and E. Piuzzi, "Specific absorption rate and temperature increases in the head of a cellular phone user," IEEE Trans. Microw. Theory Techn., vol. 48, no. 7, pp. 1118-1126, Jul. 2000.

[31] A. Ibrahiem, C. Dale, W. Tabbara, and J. Wiart, "Analysis of the temperature increase linked to the power induced by RF source," Progress Electromagn. Res., vol. 52, pp. 23-46, 2005.

[32] J. W. Hand, Y. Li, and J. V. Hajnal, "Numerical study of RF exposure and the resulting temperature rise in the foetus during a magnetic resonance procedure," Phys. Med. Biol., vol. 55, pp. 913-930, Feb. 2010.

[33] Agence française de sécurité sanitaire de l'environnement et du travail, "Les systems d'identification par radiofréquences (RFID) -Evaluation des impacts sanitaires," Saisine Afsset n 2005/013, 2009

[34] G. Schmid, R. Überbacher, S. Cecil, A. Escorihuela-Navarro, D. Sainitzer, and A. Weinfurter "Bestimmung der exposition gegenüber elektromagnetischen feldern, die durch den einsatz von radio frequency identification (RFID) technologien entstehen. abschlussbericht," Ressortforschungsberichte zur kerntechnischen Sicherheit und zum Strahlenschutz, BfSRESFOR-65/12 urn:nbn:de:0221-201208089216, 2012

[35] (2013). SEAWIND-Sound Exposure \& Risk Assessment of Wireless Network Devices. Final Summary Report. [Online]. Available: $\mathrm{http://seawind-fp7.eu/deliverables-and-publications/}$

[36] T. Joukou, J. Wang, and O. Fujiwara, "Dependence of temperature-rise in the human head on antenna input power for portable telephones," IEIC Tech. Rep., vol. 98, no. 493, pp. 1-6, 1998.

[37] A. Hirata, M. Fujumoto, T. Asano, J. Wang, O. Fujiwara, and T. Shiozawa, "Correlation between maximum temperature increase and peak SAR with different averaging schemes and masses," IEEE Trans. Electromagn. Compat., vol. 48, no. 3, pp. 569-578, Aug. 2006.
[38] M. C. Gosselin, A. Christ, S. Kühn, and N. Kuster, "Dependence of the occupational exposure to mobile phone base stations on the properties of the antenna and the human body," IEEE Trans. Electromagn. Compat., vol. 51, no. 2, pp. 227-223, May 2009.

[39] S. Kühn, W. Jennings, A. Christ, and N. Kuster, "Assessment of induced radio-frequency electromagnetic fields in various anatomical human body models," Phys. Med. Biol., vol. 54, no. 4, pp. 875-890, Feb. 2009.

[40] I. Laakso, "Assessment of computational uncertainty of temperature rise and SAR in the eyes and brain under far-field exposure from 1 to $10 \mathrm{GHz}$," Phys. Med. Biol., vol. 54, pp. 3393-3404, 2009.

[41] J. F. Bakker, M. M. Paulides, A. Christ, N. Kuster, and G. C. Van Rhoon, "Assessment of induced SAR in children exposed to electromagnetic plane waves between $10 \mathrm{MHz}$ and $5.6 \mathrm{GHz}$," Phys. Med. Biol., vol. 55, no. 11, pp. 3115-3130, May 2010.

[42] T. Samaras, A. Christ, and N. Kuster, "Effects of geometry discretization aspects on the numerical solution of the bioheat transfer equation with the FDTD technique," Phys. Med. Biol., vol. 51, pp. N221-N229, May 2006.

[43] G. Lazzi, O. Gandhi, and D. Sullivan, "Use of PML absorbing layers for the truncation of the head model in cellular telephone simulations," IEEE Trans. Microw. Theory Techn., vol. 48, no. 11, pp. 2033-2039, 2000.

[44] R.P. Findlay and P.J. Dimbylow, "Variations in calculated SAR with distance to the perfectly matched layer boundary for a human voxel model," Phys. Med. Biol., vol. 51, no. 23, pp. N411-N415, Dec. 2006.

[45] I. Laakso, S. Ilvonen, and T. Uusitupa, "Performance of convolutional PML absorbing boundary conditions in finite-difference time domain SAR calculations," Phys. Med. Biol., vol. 52, pp. 7183-7192, 2007.

[46] I. Laakso, T. Uusitupa, and S. Ilvonen, "Comparison of SAR calculation algorithms for the finite difference time-domain method," Phys. Med. Biol., vol. 55, no. 15, pp. N421-N431, Aug. 2010.

[47] B. B. Beard, W. Kainz, T. Onishi, T. Iyama, S. Watanabe, O. Fujiwara, J. Wang, G. Bit-Babik, A. Faraone, J. Wiart, A. Christ, N. Kuster, A.-K. Lee, H. Kroeze, M. Siegbahn, J. Keshvari, H. Abrishamkar, W. Simon, D. Manteuffel, and N. Nikoloski, "Comparisons of computed mobile phone induced SAR in the SAM phantom to that in anatomically correct models of the human head," IEEE Trans. Electromagn. Compat., vol. 48, no. 2, pp. 397-407, May 2006.

[48] J. Wiart, A. Hadjem, M.F. Wong, and I. Bloch, "Analysis of RF exposure in the head tissues of children and adults," Phys. Med. Biol., vol. 53, no. 13, pp. 3681-3695, 2008.

[49] C. Gabriel and A. Peyman, "Dielectric measurement error analysis and assessment of uncertainty," Phys. Med. Biol., vol. 51, no. 23, pp. 6033 6046, Dec. 2006.

[50] J. Keshvari, R. Keshvari, and S. Lang, "The effect of increase in dielectric values on specific absorption rate (SAR) in eye and head tissues following 900, 1800 and $2450 \mathrm{MHz}$ radio frequency (RF) exposure," Phys. Med. Biol., vol. 51, no. 6, pp. 1463-1467, 2006.

[51] J. Wang, O. Fujiwara, and S. Watanabe, "Approximation of aging effect on dielectric tissue properties for SAR assessment of mobile telephones," IEEE Trans. Electromagn. Compat., vol. 48, no. 2, pp. 408-413, May 2006.

[52] A. Peyman, C. Gabriel, E. H. Grant, G. Vermeeren, and L. Martens, "Variation of the dielectric properties of tissues with age: the effect on the values of SAR in children when exposed to walkie-talkie devices," Phys. Med. Biol., vol. 54, no. 2, pp. 227-241, 2009.

[53] A. Christ, M. C. Gosselin, M. Christopoulou, S. Kühn, and N. Kuster "Age-dependent tissue specific exposure of cell phone users," Phys. Med. Biol., vol. 55, no. 7, pp. 1767-1783, 2010.

[54] S. Fiocchi, M. Parazzini, and P. Ravazzani, "RFID system for newborn identity reconfirmation in hospital: exposure assessment of a realistic newborn model and effects of the change of the dielectric properties with age," Progr. Biophys. Mol. Biol, vol. 107, no. 3, pp. 443-448, Dec. 2011.

[55] S. Fiocchi, M. Parazzini, A. Paglialonga, and P. Ravazzani, "Computational exposure assessment of electromagnetic fields generated by an RFID system for mother-newborn identity reconfirmation," Biolectromagnetics, vol. 32, no. 5, pp. 408-416, Jul. 2011. 